\title{
Hypoglycemic Effect of Vitexin in C57BL/6J Mice and HepG2 Models
}

\author{
Weidong Xu $\mathbb{D}^{1},{ }^{1}$ Jiayao Li $\mathbb{D}^{1},{ }^{1}$ Weipeng Qi $\mathbb{i},^{2}$ and Ye Peng $\mathbb{D}^{3}$ \\ ${ }^{1}$ School of Pharmacy, Jiangsu University, Zhenjiang, Jiangsu Province, China \\ ${ }^{2}$ Department of Food Science, University of Massachusetts Amherst, Amherst, MA 01002, USA \\ ${ }^{3}$ School of Food and Biological Engineering, Jiangsu University, Zhenjiang, Jiangsu Province, China \\ Correspondence should be addressed to Ye Peng; leafypeng@outlook.com
}

Received 15 January 2021; Revised 30 January 2021; Accepted 22 February 2021; Published 11 March 2021

Academic Editor: Yan Zhang

Copyright $\odot 2021$ Weidong Xu et al. This is an open access article distributed under the Creative Commons Attribution License, which permits unrestricted use, distribution, and reproduction in any medium, provided the original work is properly cited.

\begin{abstract}
Apigenin-8-C-glucoside (vitexin), a natural phytochemical contained in hawthorn, has been reported to have versatile beneficial bioactivities, such as antioxidation, anticancer property, and adipogenesis inhibition. The present research aimed to determine the influence of vitexin on insulin resistance elicited by HFD in mice and HepG2 cells. Vitexin markedly alleviated body weight gain and improved glucose and insulin intolerance induced by HFD. Vitexin partially normalized blood glucose, cholesterol, TNF- $\alpha$, and hepatic lipid content. Moreover, vitexin recovered the reduced glucose uptake induced by glucosamine. The present results indicate that vitexin prevents HFD-induced insulin resistance.
\end{abstract}

\section{Introduction}

In recent years, incidence of type 2 diabetes has increased dramatically all over the world, and diabetes is usually accompanied by many systemic complications, such as heart, eye, and blood vessel diseases, which poses a great threat to patients [1]. The liver is an insulin-sensitive organ and plays an important role in maintaining glucose and lipid metabolism. Insulin resistance in the liver is closely linked with the occurrence and progression of type 2 diabetes [2]. In the liver, insulin resistance has been found to reduce glucose uptake and glycogen synthesis and to inhibit insulin signaling activation [3, 4]. HepG2 cells share the same lipid or glucose metabolism with normal hepatic cells [5]. In this metabolism, insulin activates an insulin receptor, and insulin receptor substrates are phosphorylated, which eventually leads to the activation of the PI3K/AKT pathway [6]. ER stress plays a critical role in the progression of liver insulin resistance [3]. ER stress promotes adipokine production and induces adipose tissue inflammation and dysfunction [7]. In the liver, ER stress interferes with hepatic glucose metabolism and impairs insulin sensitivity [8].
Vitexin is a natural flavonoid presenting in several consumable plants, such as hawthorn (Crataegus pinnatifida) and chayote (Sechium edule) $[9,10]$. The plants have been historically used as Chinese medicine for curing toxification, intestinal inflammation, and digestive disorders three thousand years ago $[11,12]$. Recently, a few studies reported that vitexin exhibits various bioactivities, including anti-inflammatory, anticancer, and antihypertension effects $[13,14]$. Vitexin was shown to reduce the pro-hyperalgesic cytokine level, while enhancing the anti-hyperalgesic level [15]. Vitexin was also found to ameliorate streptozotocin- or lipopolysaccharide-induced damage of the pancreas and islet tissue via the upregulation of antioxidative factors, including Nrf2 and GPx [16]. Moreover, vitexin obtained from Cynometra cauliflora Linn. increased the translocation of GLUT4 from the cell cytoplasm to membrane, indicating its beneficial potential on glucose uptake [17]. Although the protection of the pancreas and the promotion of glucose uptake by vitexin may suggest its beneficial effects on glucose homeostasis, the information of vitexin on insulin resistance and hepatic ER stress response is scarce. Animal studies reported that HFD-induced obesity is closely associated with insulin resistance $[18,19]$. Also, glucosamine has been 
widely used to induce ER stress in vitro [4]. Thus, the present research aimed to determine vitexin's influence on HFD and glucosamine-elicited insulin resistance in $\mathrm{C} 57 \mathrm{BL} / 6 \mathrm{~J}$ mice and in HepG2 cells.

\section{Materials and Methods}

2.1. Materials. HepG2 were bought from the Shanghai Cell Bank of the Chinese Academy of Sciences (Shanghai, China). Vitexin with purity $\geq 98 \%$ was purchased from Pufei De Biotech Co., Ltd. (Chengdu, Sichuan Province, China). FBS, DMEM, dimethyl sulfoxide, insulin, and glucosamine were purchased from Sigma-Aldrich (St. Louis, MO, USA). Glucose meter (GLM-75) and test strips were obtained from GlucoLeader (Beijing, China).

2.2. Animals and Diets. C57BL/6J male mice (10 week) were purchased from Jiangsu University Laboratory Animal Research Center (Jiangsu, China) and housed in the animal facility under standard conditions (12/12 h light-dark cycle). All animal experimental procedures were followed according to the Guide for the Care and Use of Laboratory Animals: Eighth Edition, ISBN-10: 0-309-15396-4, and the animal protocol was approved by the Jiangsu University Animal Ethics Committee. After a two-week adaptation, mice were separated into 3 groups ( 9 mice per group): LFD, $\mathrm{HFD}$, and HFD + Vitexin ( $5 \mathrm{mg}$ vitexin/kg BW/day) for 8 weeks. The HFD (60\% of energy from fat, TP23400) and LFD (10\% kcal from fat, TP23402) were from Trophic Animal Feed High-tech Co., Ltd. (Nantong, Jiangsu Province, China). The vitexin dose was based on a previous study [20].

At the end of the study, mice were fasted overnight before being sacrificed by $\mathrm{CO}_{2}$ asphyxiation. Blood was collected by cardiac puncture. Serum was obtained from blood by centrifugation for $20 \mathrm{~min}$ at $2000 \mathrm{rpm}$. Part of the liver was fixed in buffered formalin (10\%). The ITT and GTT were performed as previously described [21].

\subsection{Serum Parameters and Liver Triglycerides Quantitation.} The TG from the liver and serum and serum glucose levels were quantified using commercial kits according to manufacturers' instructions (Nanjing Jiancheng Bioengineering Institute, Nanjing, Jiangsu Province, China). The level of serum TNF- $\alpha$ was detected using the ELISA kits (FcMACS Co., Ltd, Nanjing, Jiangsu Province, China).

2.4. Cell Culture. HepG2 cells were maintained as previously reported [22]. After incubation with $18 \mathrm{~mm}$ glucosamine for $18 \mathrm{~h}$ to induce insulin resistance [4], the HepG2 cells were serum-starved for $2 \mathrm{~h}$ and then incubated with vitexin $(20 \mu \mathrm{M})$ for $24 \mathrm{~h}$, with $100 \mathrm{nM}$ insulin added in the last $15 \mathrm{~min}$. The vitexin and glucosamine concentrations were in accordance with previous publications [4, 20], and the concentrations had no influence on cell viability as determined by the MTT assay, as previously reported [23, 24]. Glucosamine was dissolved in PBS, and vitexin was dissolved in DMSO. All groups had the same amount of DMSO.
2.5. Glucose Uptake Assay. Glucose uptake measurement was performed with a fluorescent glucose derivative, 2NBDG, as previously reported [25]. There were three treatment groups, i.e., Control, Glucosamine, and Glucosamine + Vitexin groups. Briefly, HepG2 cells were treated with or without $18 \mathrm{mM}$ glucosamine for $18 \mathrm{~h}$ and starved in F-12K (5.5 mM glucose) serum-free media for $2 \mathrm{~h}$. Then, cells were treated with or without $20 \mu \mathrm{M}$ vitexin for $24 \mathrm{~h}$ following the treatment of $100 \mathrm{nM}$ insulin for $15 \mathrm{~min}$ (serum-free medium). After washing, the fluorescent signal was quantified with a plate reader at excitation/emission of 465/ $540 \mathrm{~nm}$ (SpectraMax i3, Shanghai, China) and normalized by protein content (BCA protein assay kit, Beyotime Biotechnology Inc. Shanghai, China).

2.6. Statistical Analyses. Data were analyzed with one-way ANOVA (Tukey's multiple-range test) with SAS software (SAS Institute Inc., Cary, NC, USA). A $P<0.05$ was considered statistically significant.

\section{Results}

3.1. Vitexin Decreased Body Weight in HFD-Treated Mice. As shown in Figure 1(a), the HFD group possessed higher body weight than the LFD and HFD + Vitexin groups during week 8 . The HFD + Vitexin group had no significantly different body weight compared to the LFD group. All three groups had similar total food intake (Figure 1(b)).

\subsection{Vitexin Improved Glucose Homeostasis. ITT and GTT} were performed to determine the influence of vitexin on glucose metabolism, and results are shown in Figure 2. For the ITT, HFD-fed mice had a higher blood glucose level than mice fed with LFD at all points in time (Figure 2(a)). Compared to the HFD-fed mice, vitexin significantly reduced the HFD-induced blood glucose increase after $0,15,30,60$, and 120 minutes (Figure 2(a)). Similarly, HFD significantly increased the AUC of the ITT, and the AUC was significantly reduced by vitexin treatment (Figure 2(b)). For the GTT results, mice fed with a HFD had a significantly higher blood glucose level at 15, 30 , and 60 minutes, as well as the AUC, than in the LFD group and the HFD + Vitexin group (Figures 2(c) and 2(d)). The results indicate that vitexin significantly alleviated insulin and glucose intolerance induced by the HFD.

3.3. Effects of Vitexin on Serum Markers. As shown in Table 1, in HFD-fed mice, the glucose and TG levels were significantly increased compared with the LFD-fed mice and were markedly decreased in the HFD + Vitexin group. In addition, vitexin reduced the HFD-induced TNF- $\alpha$ level. No differences were observed for the three parameters between the LFD and HFD + Vitexin groups.

3.4. Vitexin Reduced Liver Fat Content. The H\&E staining results (Figure 3(a)) directly showed the difference of lipid content in the liver tissue in each group of mice. Mice fed with HFD had higher liver fat content than mice fed with the 


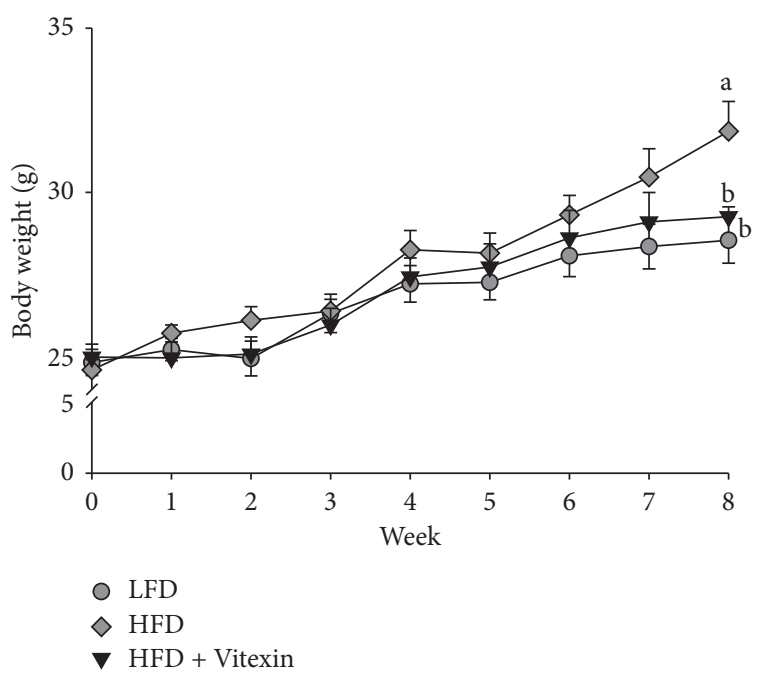

(a)

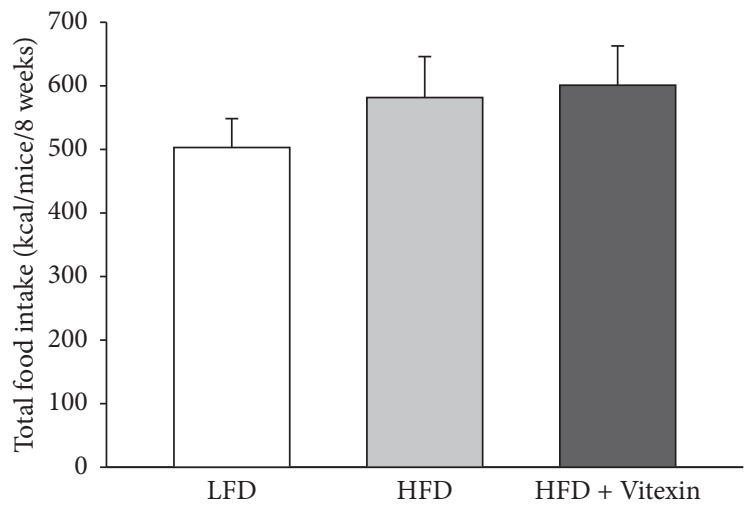

(b)

Figure 1: Influence of vitexin on body weight and food intake. Mice were fed with low-fat diet (LFD), high-fat diet (HFD), or HFD supplemented with $5 \mathrm{mg}$ vitexin/kg BW/day (HFD + Vitexin) for 8 weeks. (a) Body weight monitored weekly; (b) total food intake. Numbers indicate mean \pm SE $(n=8-9$ for (a) and $n=3$ for (b)). Means with different letters were significantly different at $P<0.05$.

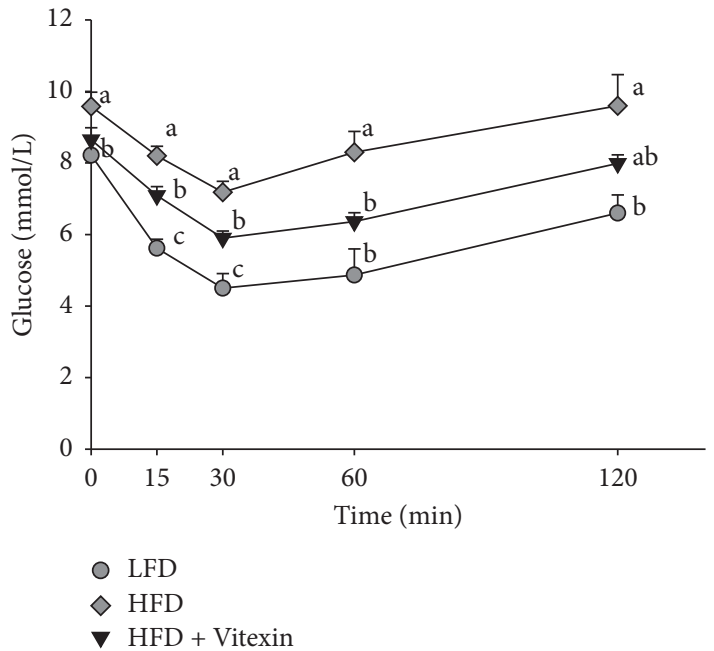

(a)

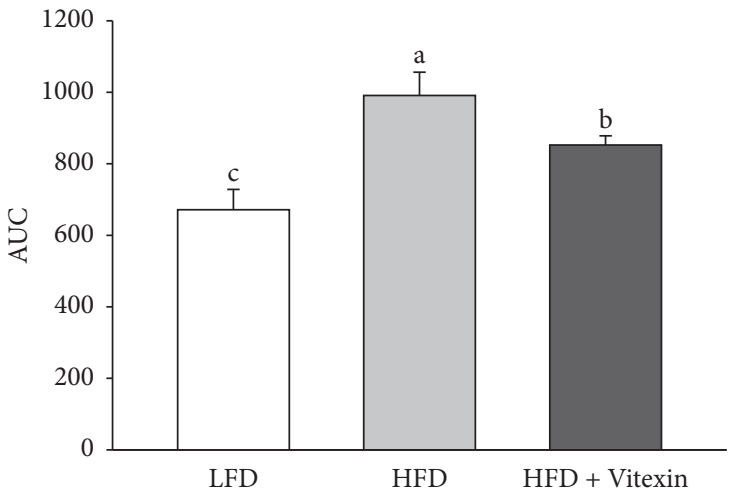

(b)

Figure 2: Continued. 


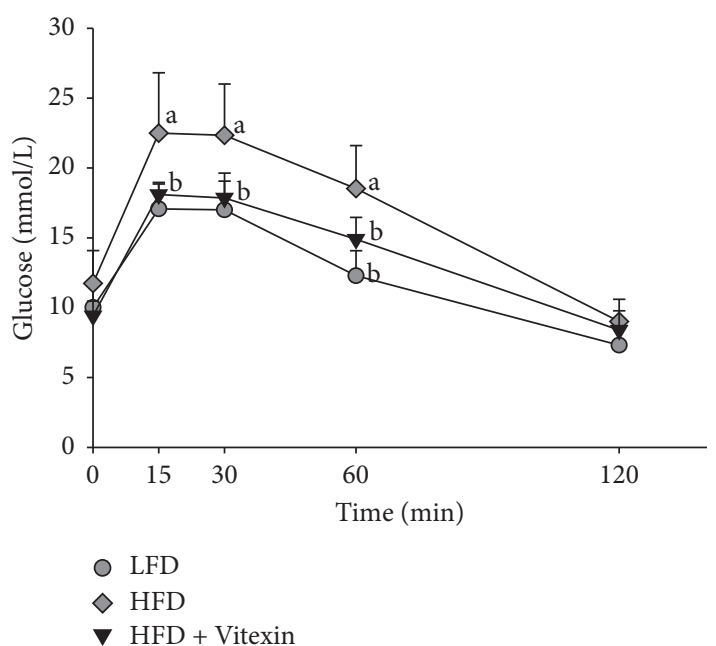

(c)

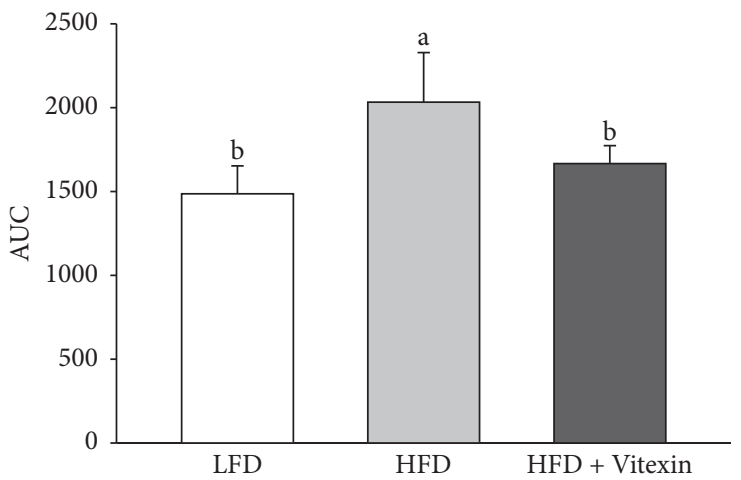

(d)

FIGURE 2: Influence of vitexin on insulin tolerance test (ITT) ( $a, b)$ and glucose tolerance test (GTT) (c, d). Mice were fed with low-fat diet (LFD), high-fat diet (HFD) or HFD supplemented with $5 \mathrm{mg}$ vitexin/kg BW/day (HFD + Vitexin) for 8 weeks. Blood was collected from the tail vein, and glucose levels were determined at $0 \mathrm{~min}$. Insulin (ITT) or glucose solutions (GTT) were subsequently administered by intraperitoneal injection, and the glucose level was further measured at 15, 30, 60, and 120 min after injection. Data were expressed as the mean \pm SE $(n=5-7)$. Means with different letters were significantly different at $P<0.05$.

TABLE 1: Serum parameters.

\begin{tabular}{lccc}
\hline & LFD & HFD & HFD + Vitexin \\
\hline Glucose $(\mathrm{mg} / \mathrm{dl})$ & $162.0 \pm 5.7$ & $202.6 \pm 4.3^{*}$ & $175.1 \pm 9.6^{\#}$ \\
TG $(\mathrm{mg} / \mathrm{dl})$ & $52.5 \pm 5.0$ & $80.3 \pm 3.0^{*}$ & $66.3 \pm 2.7^{\#}$ \\
TNF- $\alpha(\mathrm{pg} / \mathrm{ml})$ & $18.1 \pm 2.9$ & $49.3 \pm 6.6^{*}$ & $31.9 \pm 2.7^{\#}$ \\
\hline
\end{tabular}

Serum levels of glucose, TG, and proinflammatory cytokines including TNF- $\alpha$ in mice fed with a LFD, a HFD and a HFD with $5 \mathrm{mg} / \mathrm{kg}$ BW/day vitexin. LFD, low-fat diet; HFD, high-fat diet; HFD + Vitexin, high-fat diet plus vitexin at $5 \mathrm{mg} / \mathrm{kg}$ BW/day. Values represent means \pm SE $(n=8-9) .{ }^{*} P<0.05 \mathrm{vs}$. LFD; ${ }^{\#} P<0.05$ vs. HFD.
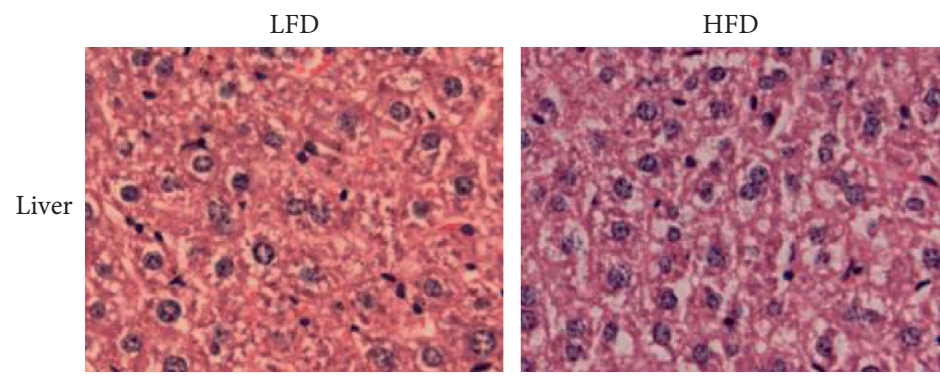

(a)

FIGURE 3: Continued.

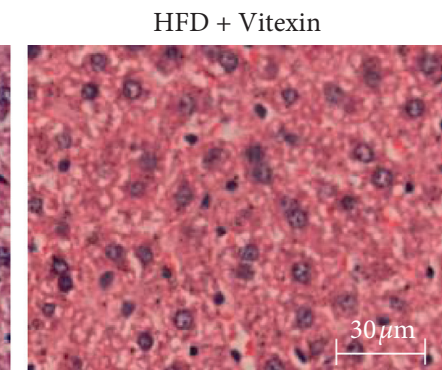

\section{.}

FIGURE 3: Continued. 


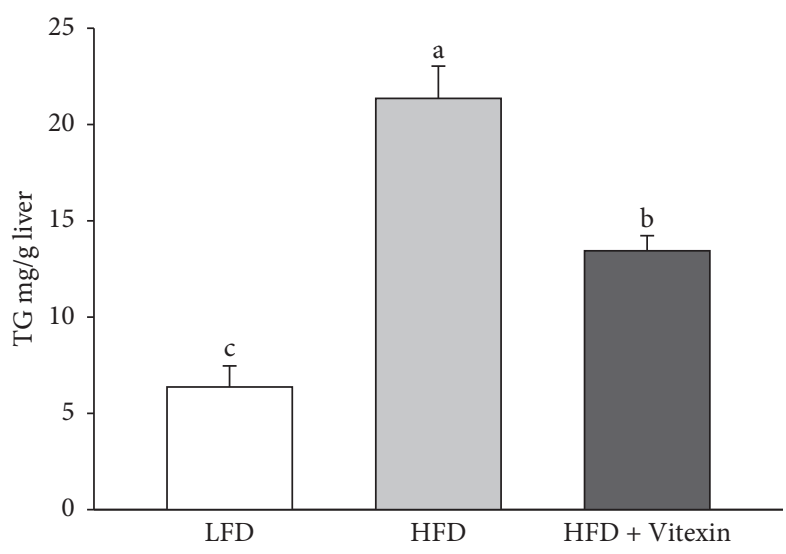

(b)

FIGURE 3: Effects of vitexin on liver morphology and triglyceride level. Mice were fed with low-fat diet (LFD), high-fat diet (HFD) or HFD containing $5 \mathrm{mg}$ vitexin/kg BW/day (HFD + Vitexin) for 8 weeks. (a) Representative pictures of the liver after H\&E staining; (b) liver triglyceride. Data were expressed as the mean \pm SE $(n=4)$. Means with different letters were significantly different at $P<0.05$.

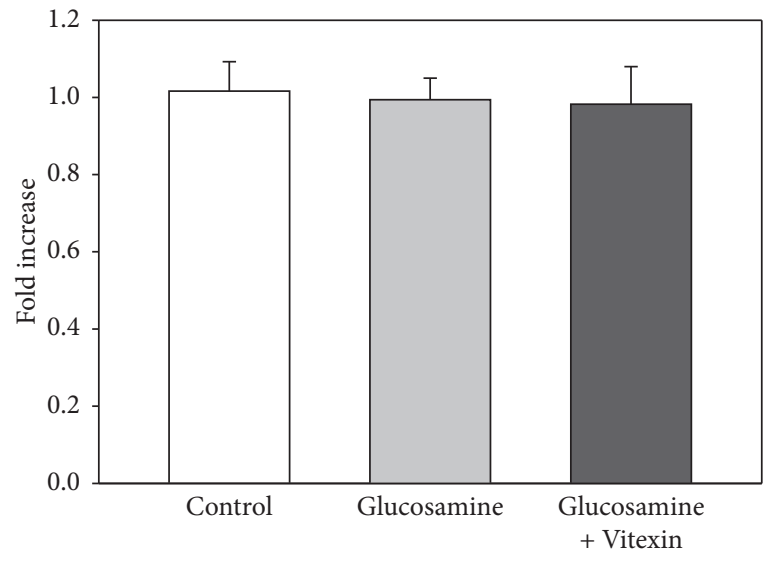

(a)

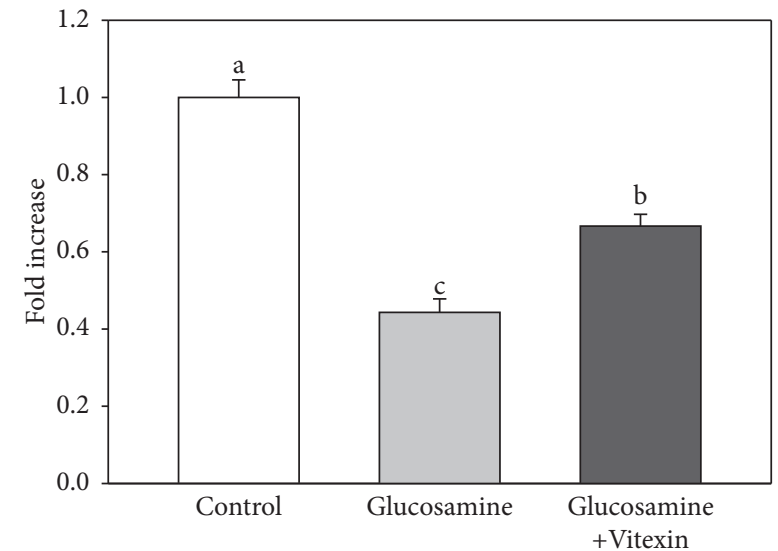

(b)

FIgUre 4: Influence of vitexin on cell viability and glucose uptake in HepG2 cells. (a) Cell viability; (b) triglyceride content. Numbers represent mean $\pm \mathrm{SE}(n=3)$. Means with different letters were significantly different at $P<0.05$.

LFD, and the liver fat content was significantly reduced by vitexin treatment (Figure 3(b)).

\subsection{Influence of Vitexin and Glucosamine on Cell Viability and} Glucose Uptake in HepG2 Cells. Glucosamine (18 mM) and vitexin $(20 \mu \mathrm{M})$ did not affect cell viability (Figure $4(\mathrm{a})$ ). Reduced glucose uptake is an important marker of insulin resistance [26]. Glucosamine reduced glucose uptake by $56 \%$ compared to the control, while vitexin recovered glucose uptake by $50 \%$ compared to the glucosamine group (Figure 4(b)). These results suggested that vitexin alleviated glucose uptake reduction induced by glucosamine.

\section{Discussion}

Our present research demonstrated that vitexin improved $\mathrm{HFD}$-induced insulin resistance in C57BL/6J male mice and recovered glucosamine-induced glucose uptake reduction.
In the present study, vitexin significantly recovered insulin tolerance and glucose tolerance impaired by HFD, and it increased glucose uptake reduced by glucosamine treatment, which are consistent with a previous study showing that oral administration of 1 to $200 \mathrm{mg}$ vitexin $/ \mathrm{kg}$ body weight effectively reduced the blood glucose level in sucrose-loaded mice $[27,28]$. Excessive accumulation of fat and insulin resistance is closely linked with inflammation, as with excess TNF- $\alpha$ release [29]. Vitexin contained in mung bean extracts reduced the intramuscular TNF- $\alpha$ in KK-Ay diabetic mice [30]. Vitexin also inhibited TNF- $\alpha$ production in LPS-treated rats and pancreatic $\beta$-cells [31]. Consistent with the studies, the current research demonstrated that vitexin potently reduced the serum TNF- $\alpha$ level induced by a $\mathrm{HFD}$ in $\mathrm{C} 57 \mathrm{BL} / 6 \mathrm{~J}$ mice.

Knowledge of serum vitexin concentration in human metabolism is limited, while the bioavailability of vitexin is relatively low [32]. The absolute bioavailability of vitexin is only around $4.9 \%$ when rats are orally administered with 
$30 \mathrm{mg} / \mathrm{kg}$ vitexin [33]. The vitexin concentration we used in the current in vitro study might be relatively high. Studies to increase vitexin's bioavailability are therefore necessary to better utilize vitexin as a functional food ingredient.

In summary, vitexin improved HFD-triggered insulin resistance and reduced hepatic fat accumulation in C57 BL/ $6 \mathrm{~J}$ mice. Therefore, vitexin can be considered as a potential functional food ingredient which may be combined with preventive strategies to alleviate insulin resistance and type 2 diabetes.

\section{Abbreviations}

$\begin{array}{ll}\text { HFD: } & \text { High-fat diet } \\ \text { LFD: } & \text { Low-fat diet } \\ \text { HFD + vitexin: } & \text { HFD with } 5 \mathrm{mg} \text { vitexin/kg BW/day } \\ \text { AKT: } & \text { Protein kinase B } \\ \text { AUC: } & \text { Area under the curve } \\ \text { DMEM: } & \text { Dubelco's modified Eagle's medium } \\ \text { FBS: } & \text { Fetal bovine serum } \\ \text { GPx: } & \text { Glutathione peroxidase } \\ \text { GTT: } & \text { Glucose tolerance test } \\ \text { ITT: } & \text { Insulin tolerance test } \\ \text { 2-NBDG: } & \text { 2-(N-(7-Nitrobenz-2-oxa-1,3-diazol-4-yl) } \\ & \text { amino-2-deoxyglucose } \\ \text { PBS: } & \text { Phosphate-buffered saline } \\ \text { RIPA: } & \text { Radioimmunoprecipitation assay } \\ \text { TG: } & \text { Triglyceride } \\ \text { TNF- } \alpha: & \text { Tumor necrosis factor. }\end{array}$

\section{Data Availability}

The data used to support the findings of this study are available from the corresponding author upon request.

\section{Conflicts of Interest}

The authors declare that they have no conflicts of interest.

\section{References}

[1] N. M. Maruthur, "The growing prevalence of type 2 diabetes: increased incidence or improved survival?" Current Diabetes Reports, vol. 13, no. 6, pp. 786-794, 2013.

[2] M. H. Park and J.-S. P. Han, "Padina arborescens ameliorates hyperglycemia and dyslipidemia in C57BL/KsJ-db/db mice, a model of type 2 diabetes mellitus," Journal of Medicinal Food, vol. 18, no. 10, pp. 1088-1094, 2015.

[3] M. Flamment, E. Hajduch, P. Ferré, and F. Foufelle, "New insights into ER stress-induced insulin resistance," Trends in Endocrinology \& Metabolism, vol. 23, no. 8, pp. 381-390, 2012.

[4] D. Zhu, Y. Wang, Q. Du, Z. Liu, and X. Liu, "Cichoric acid reverses insulin resistance and suppresses inflammatory responses in the glucosamine-induced HepG2 cells," Journal of Agricultural and Food Chemistry, vol. 63, no. 51, pp. 1090310913, 2015.

[5] J. Xu, M. Ma, and W. M. Purcell, "Characterisation of some cytotoxic endpoints using rat liver and HepG2 spheroids as in vitro models and their application in hepatotoxicity studies. II. Spheroid cell spreading inhibition as a new cytotoxic marker," Toxicology and Applied Pharmacology, vol. 189, no. 2, pp. 112-119, 2003.

[6] P. J. Klover and R. A. Mooney, "Hepatocytes: critical for glucose homeostasis," The International Journal of Biochemistry \& Cell Biology, vol. 36, no. 5, pp. 753-758, 2004.

[7] S. Ding, J. Jiang, Z. Wang et al., "Resveratrol reduces the inflammatory response in adipose tissue and improves adipose insulin signaling in high-fat diet-fed mice," PeerReviewed journal, vol. 6, Article ID e5173, 2018.

[8] M. Latreille, M.-K. Laberge, G. Bourret, L. Yamani, and L. Larose, "Deletion of Nck1 attenuates hepatic ER stress signaling and improves glucose tolerance and insulin signaling in liver of obese mice," American Journal of PhysiologyEndocrinology and Metabolism, vol. 300, no. 3, pp. E423E434, 2011.

[9] M. Liang, W. Xu, W. Zhang et al., "Quantitative LC/MS/MS method and in vivo pharmacokinetic studies of vitexin rhamnoside, a bioactive constituent on cardiovascular system from hawthorn," Biomedical Chromatography, vol. 21, no. 4, pp. 422-429, 2007.

[10] T. Siciliano, N. De Tommasi, I. Morelli, and A. Braca, "Study of flavonoids of Sechium edule(jacq) swartz (cucurbitaceae) different edible organs by liquid chromatography photodiode array mass spectrometry," Journal of Agricultural and Food Chemistry, vol. 52, no. 21, pp. 6510-6515, 2004.

[11] K. Ganesan and B. Xu, "A critical review on phytochemical profile and health promoting effects of mung bean (Vigna radiata)," Food Science and Human Wellness, vol. 7, no. 1, pp. 11-33, 2018.

[12] D. Kumar, V. Arya, Z. A. Bhat, N. A. Khan, and D. N. Prasad, "The genus crataegus: chemical and pharmacological perspectives," Revista Brasileira de Farmacognosia, vol. 22, no. 5, pp. 1187-1200, 2012.

[13] E. Díaz-de-Cerio, V. Verardo, A. Fernández-Gutiérrez, and A. M. Gómez-Caravaca, "New insight into phenolic composition of chayote (sechium edule (jacq.) sw.)," Food Chemistry, vol. 295, pp. 514-519, 2019.

[14] E. F. Vieira, O. Pinho, I. M. P. L. V. O. Ferreira, and C. Delerue-Matos, "Chayote (sechium edule): a review of nutritional composition, bioactivities and potential applications," Food Chemistry, vol. 275, pp. 557-568, 2019.

[15] S. M. Borghi, T. T. Carvalho, L. Staurengo-Ferrari et al., "Vitexin inhibits inflammatory pain in mice by targeting TRPV1, oxidative stress, and cytokines," Journal of Natural Products, vol. 76, no. 6, pp. 1141-1149, 2013.

[16] S. Nurdiana, Y. M. Goh, H. Ahmad et al., "Changes in pancreatic histology, insulin secretion and oxidative status in diabetic rats following treatment with Ficus deltoidea and vitexin," BMC Complementary and Alternative Medicine, vol. 17, p. 290, 2017.

[17] A. Seyedan, Z. Mohamed, M. A. Alshagga, S. Koosha, and M. A. Alshawsh, "Cynometra cauliflora Linn. Attenuates metabolic abnormalities in high-fat diet-induced obese mice," Journal of Ethnopharmacology, vol. 236, pp. 173-182, 2019.

[18] Z. Liu, I. Y. Patil, T. Jiang et al., "High-fat diet induces hepatic insulin resistance and impairment of synaptic plasticity," PLoS One, vol. 10, Article ID e0128274, 2015.

[19] Q. Sun, X. Xiao, Y. Kim et al., "Imidacloprid promotes high fat diet-induced adiposity and insulin resistance in male C57bl/6J mice," Journal of Agricultural and Food Chemistry, vol. 64, no. 49, pp. 9293-9306, 2016.

[20] Y. Peng, Q. Sun, W. Xu et al., "Vitexin ameliorates high fat diet-induced obesity in male C57BL/6J mice via the AMPKx- 
mediated pathway," Food \& Function, vol. 10, no. 4, pp. 1940-1947, 2019.

[21] Q. Sun, W. Qi, X. Xiao et al., "Imidacloprid promotes high fat diet-induced adiposity in female C57bl/6J mice and enhances adipogenesis in 3T3-L1 adipocytes via the AMPK $\alpha$-mediated pathway," Journal of Agricultural and Food Chemistry, vol. 65, no. 31, pp. 6572-6581, 2017.

[22] J. S. Yang, W. Qi, R. Farias-Pereira et al., "Permethrin and ivermectin modulate lipid metabolism in steatosis-induced HepG2 hepatocyte," Food and Chemical Toxicology, vol. 125, pp. 595-604, 2019.

[23] L. Yuan, J. Lin, Y. Xu et al., "Deltamethrin promotes adipogenesis via AMPK $\alpha$ and ER stress-mediated pathway in 3T3- L1 adipocytes and Caenorhabditis elegans," Food and Chemical Toxicology, vol. 134, Article ID 110791, 2019.

[24] T. Mosmann, "Rapid colorimetric assay for cellular growth and survival: application to proliferation and cytotoxicity assays," Journal of Immunological Methods, vol. 65, no. 1-2, pp. 55-63, 1983.

[25] Y. Peng, Q. Sun, and Y. Park, "Chicoric acid promotes glucose uptake and Akt phosphorylation via AMP-activated protein kinase $\alpha$-dependent pathway," Journal of Functional Foods, vol. 59, pp. 8-15, 2019.

[26] W. Y. Zhang, J.-J. Lee, I.-S. Kim, Y. Kim, and C.-S. Myung, "Stimulation of glucose uptake and improvement of insulin resistance by aromadendrin," Pharmacology, vol. 88, no. 5-6, pp. 266-274, 2011.

[27] C. Y. Choo, N. Y. Sulong, F. Man, and T. W. Wong, "Vitexin and isovitexin from the Leaves of Ficus deltoidea with in-vivo $\alpha$-glucosidase inhibition," Journal of Ethnopharmacology, vol. 142, no. 3, pp. 776-781, 2012.

[28] W. Xu, M. Xiao, J. Li et al., "Hepatoprotective effects of di Wu Yang Gan: a medicinal food against CCl4-induced hepatotoxicity in vivo and in vitro," Food Chemistry, vol. 327, Article ID 127093, 2020.

[29] M. S. Ellulu, I. Patimah, H. Khaza'ai, A. Rahmat, and Y. Abed, "Obesity and inflammation: the linking mechanism and the complications," Archives of Medical Science, vol. 4, pp. 851863, 2017.

[30] I. Kang, S. Choi, T. J. Ha et al., "Effects of mung bean (Vigna radiata $L$.) ethanol extracts decrease proinflammatory cytokine-induced lipogenesis in the KK-ay diabese mouse model," Journal of Medicinal Food, vol. 18, no. 8, pp. 841-849, 2015.

[31] F. Wang, J. Yin, Y. Ma, H. Jiang, and Y. Li, "Vitexin alleviates lipopolysaccharide-induced islet cell injury by inhibiting HMGB1 release," Molecular Medicine Reports, vol. 15, no. 3, pp. 1079-1086, 2017.

[32] H.-F. Xue, Z.-M. Ying, W.-J. Zhang, Y.-H. Meng, X.-X. Ying, and T.-G. Kang, "Hepatic, gastric, and intestinal first-pass effects of vitexin in rats," Pharmaceutical Biology, vol. 52, no. 8, pp. 967-971, 2014.

[33] Y. Wang, "Pharmacokinetics of vitexin in rats after intravenous and oral administration," African Journal of Pharmacy and Pharmacology, vol. 6, 2012. 